\title{
EFEITO DOS PARÂMETROS DE RECOZIMENTO CONTÍNUO NA MICROESTRUTURA E PROPRIEDADES MECÂNICAS DE UM AÇO REVESTIDO POR IMERSÃO A QUENTE DA CLASSE DE RESISTÊNCIA DE 800 Mpa*
}

Gislan William Guimarães ${ }^{1}$ Paulo Roberto Cetlin ${ }^{2}$

Roberta de Oliveira Rocha ${ }^{3}$ Jetson Lemos Ferreira ${ }^{4}$

\section{Resumo}

Neste trabalho avaliou-se o efeito de diferentes ciclos térmicos na microestrutura e propriedades mecânicas de um aço Dual Phase revestido por imersão a quente, da classe de resistência de $800 \mathrm{MPa}$, a partir de simulações em escala piloto no equipamento HDPS (Hot Dip Process Simulator), ensaios dilatométricos, tração à temperatura ambiente e flangeamento. Nas simulações de recozimento contínuo foram experimentadas duas temperaturas de encharque no recozimento intercrítico $\left(740^{\circ} \mathrm{C}\right.$ e $\left.780^{\circ} \mathrm{C}\right)$ e três temperaturas de patamar isotérmico no resfriamento rápido $\left(610^{\circ} \mathrm{C}, 560^{\circ} \mathrm{C}\right.$ e $\left.510^{\circ} \mathrm{C}\right)$. A caracterização microestrutural evidenciou que a temperatura de encharque de $740^{\circ} \mathrm{C}$ não foi suficiente para dissolução completa dos carbonetos formados na laminação a quente, resultando em frações reduzidas de segundo constituinte. Com isso, o limite de resistência mínimo de $800 \mathrm{MPa}$ não foi alcançado. Além disso, os resultados de ductilidade e flangeamento se mostraram aquém dos obtidos nas simulações com encharque a $780^{\circ} \mathrm{C}$. Nas simulações com temperatura de encharque a $780^{\circ} \mathrm{C}$ e isotérmicas de $510^{\circ} \mathrm{C}$ e $560^{\circ} \mathrm{C}$ no resfriamento rápido foi atendido o limite de resistência mínimo, com capacidade de expansão de furo ligeiramente superior à obtida nas simulações com encharque a $740^{\circ} \mathrm{C}$.

Palavras-chave: Aços avançados de alta resistência; Dual phase; Recozimento contínuo.

\section{EFFECT OF CONTINUOUS ANNEALING PARAMETERS ON MICROSTRUCTURE AND MECHANICAL PROPERTIES OF A HOT DIP GALVANIZED STEEL OF THE $800 \mathrm{MPa}$ STRENGTH CLASS}

\section{Abstract}

In this work was evaluated the effect of different thermal cycles on the microstructures and mechanical properties of a hot dip galvanized Dual Phase steel, class $800 \mathrm{MPa}$, from simulations in laboratory scale with the equipment HDPS (Hot Dip Process Simulator), dilatometric test, tensile test and flanging test. In the continuous annealing simulations were tested two soaking temperature $\left(740^{\circ} \mathrm{C}\right.$ and $\left.780^{\circ} \mathrm{C}\right)$ and three isothermal temperatures in the rapid cooling $\left(610^{\circ} \mathrm{C}, 560^{\circ} \mathrm{C}\right.$ and $510^{\circ} \mathrm{C}$ ). Microstructural characterization showed that the soaking temperature at $740^{\circ} \mathrm{C}$ was not enough for the complete dissolution of carbides, resulting in lower fractions of the second constituent. Thus, the minimum tensile strength was not reached. Furthermore, the ductility and flanging were lower compared to soaking temperature at $780^{\circ} \mathrm{C}$. In the thermal cycles at $780^{\circ} \mathrm{C}$ and isothermal temperature at $510^{\circ} \mathrm{C}$ and $560^{\circ} \mathrm{C}$ in the rapid cooling the minimum tensile strength was reached, hole expansion was slightly higher compared to soaking temperature at $740^{\circ} \mathrm{C}$.

Keywords: Advanced high strength steels; Dual phase; Continuous annealing.

\footnotetext{
Engenheiro de Produção; Controle Integrado da Qualidade, Usiminas, Ipatinga, MG, Brasil. Engenheiro Mecânico, Dr.; Engenharia Metalúrgica e de Materiais da UFMG, Belo Horizonte, MG. Engenheira Metalurgista, Dra.; Controle Integrado da Qualidade, Usiminas, Ipatinga, MG, Brasil.

Engenheiro Metalurgista, MSc.; Centro de Tecnologia, Usiminas, Ipatinga, MG, Brasil.
} 


\section{INTRODUÇÃO}

Nos últimos anos foi alcançado significativo progresso na diversificação das aplicações de aços avançados de alta resistência, basicamente norteada pela indústria automobilística, consolidando-os mundialmente como principal alternativa na redução do peso veicular, aliado ao aumento da durabilidade e segurança das carrocerias de automóveis.

Em 2012 o Governo Federal do Brasil, ciente que o setor automobilístico nacional se destaca como grande fomentador de pesquisas científicas e disseminador de novas tecnologias, representando mais de $22 \%$ do PIB industrial e $5 \%$ do PIB do país, apresentou as regras do novo regime automotivo, o Inovar Auto, que vigorará entre 2013 e 2017. Seu objetivo junto ao setor será a construção de veículos mais modernos, leves e eficientes quanto à emissão de carbono. As empresas que se habilitarem ao programa poderão se beneficiar com a isenção de impostos. A meta estipulada pelo governo aos fabricantes para 2017 é obter um consumo médio de $17,26 \mathrm{~km} / \mathrm{l}$ de gasolina (atualmente, $14 \mathrm{~km} / \mathrm{l})$. No caso do álcool (etanol), a meta será em 2016 obter um consumo de 11,96 km/l (atualmente, 9,7 km/l). Maiores benefícios fiscais poderão ser conquistados pelos fabricantes se superadas as metas de investimentos em inovação, engenharia de produção e componentes industriais neste período. Destaca-se ainda que o Brasil é o quinto maior fabricante mundial de automóveis.

Uma alternativa provida pelo setor siderúrgico à cadeia automotiva foi o desenvolvimento dos aços bifásicos, os quais são caracterizados por uma microestrutura constituída de ilhas de martensita dispersas em uma matriz ferrítica, podendo apresentar pequenas quantidades de outros constituintes. Como principais características, eles apresentam elevada resistência mecânica, baixa razão elástica e bons níveis de alongamento uniforme e total, habilitando-os à confecção de peças estruturais mais leves. Contudo, para fabricação destes aços com alto nível de qualidade é necessário compreender precisamente o comportamento das transformações de fases, com ênfase na composição química e nos tratamentos térmicos, em especial na taxa de resfriamento, visando a obtenção de microestrutura adequada à aplicação do produto final [1].

Neste trabalho avaliou-se o efeito de diferentes ciclos térmicos na microestrutura e propriedades mecânicas de um aço Dual Phase revestido por imersão a quente, da classe de resistência de $800 \mathrm{MPa}$, a partir de simulações em escala piloto no equipamento HDPS (Hot Dip Process Simulator) e ensaios dilatométricos, objetivando investigar quais parâmetros de processo terão maior probabilidade de êxito em escala industrial, baseando-se na caracterização microestrutural e nos resultados de tração à temperatura ambiente e flangeamento.

\section{MATERIAIS E MÉTODOS}

Foram coletadas amostras de bobina laminada a frio não recozida de espessura $1,50 \mathrm{~mm}$, a partir da composição química apresentada na tabela 1 .

Tabela 1. Especificação de Composição Química

\begin{tabular}{ccccc}
\hline \multicolumn{5}{c}{ Especificações de Composição Química } \\
\hline$\% \mathrm{C}$ & $\% \mathrm{Mn}$ & $\% \mathrm{Cr}+\% \mathrm{Mo}$ & $\% \mathrm{Ti}+\% \mathrm{Nb}$ & $\% \mathrm{~B}$ \\
\hline$\leq 0,15$ & $\leq 2,50$ & $\leq 0,45$ & $\leq 0,05$ & $\leq 0,0040$ \\
\hline
\end{tabular}


As amostras foram submetidas a diferentes ciclos térmicos utilizados no processamento de aços de revestimento GI (Galvanized - Zn puro) em linha de galvanização por imersão a quente, utilizando o equipamento HDPS do Centro de Tecnologia da USIMINAS. Optou-se pelas simulações nesse equipamento devido a área útil de seus corpos de prova (aproximadamente $220 \times 140 \mathrm{~mm}$ ) possibilitar a realização dos ensaios de tração à temperatura ambiente e de expansão cônica de furo (flangeamento).

\subsection{Simulação de Recozimento Intercrítico}

Nas simulações foram experimentadas duas temperaturas de encharque (Soaking Temperature (ST): $740^{\circ} \mathrm{C}$ e $780^{\circ} \mathrm{C}$ ) e três temperaturas de patamar isotérmico no resfriamento rápido $\left(610^{\circ} \mathrm{C}, 560^{\circ} \mathrm{C}\right.$ e $\left.510^{\circ} \mathrm{C}\right)$, assim totalizando a simulação de seis ciclos térmicos distintos. A taxa de aquecimento foi linear. Cabe ressaltar que nas simulações no HDPS as amostras não foram revestidas com zinco após o recozimento contínuo, pois não se pretendia avaliar a influência do revestimento nos resultados de expansão cônica de furo (flangeamento).

A representação esquemática e os parâmetros de recozimento intercrítico dos ciclos térmicos simulados no HDPS são apresentados na figura 1.



Figura 1. Representação esquemática dos ciclos térmicos simulados no equipamento HDPS.

Foram realizados ensaios dilatométricos visando determinar as temperaturas de início $\left(A_{1}\right)$ e final $\left(A_{3}\right)$ de transformação austenítica, assim como a fração de austenita formada ao final das duas isotérmicas de encharque no recozimento intercrítico $\left(\mathrm{ST}: 740^{\circ} \mathrm{C}\right.$ e $\left.780^{\circ} \mathrm{C}\right)$, mediante a têmpera das amostras com gás hélio.

\subsection{Caracterização Microestrutural}

A caracterização microestrutural das amostras simuladas com (1) ciclos térmicos completos no HDPS e (2) ciclos interrompidos no final das isotérmicas de encharque (ST: $740^{\circ} \mathrm{C}$ e $780^{\circ} \mathrm{C}$ ), via dilatometria, foram realizadas a partir de microscopia óptica (MO) e microscopia eletrônica de varredura (MEV). Para determinação da fração volumétrica de constituintes por metalografia quantitativa utilizou-se nital $(4 \%)$ para classificação da microestrutura em ferrita e segundo constituinte. Em relação à 
classificação da martensita foi utilizado ataque com metabissulfito de sódio $(2 \%$, Le Pera).

\subsection{Determinação das Propriedades Mecânicas em Tração}

As amostras simuladas na dimensão $220 \times 140 \mathrm{~mm}$ deram origem a três corpos de prova na direção longitudinal de laminação, preparados de acordo a norma ASTMA370 [2], de tamanho reduzido (sub-size). Os ensaios foram realizados em uma máquina Instron, modelo 5882, equipada com extensômetro de $25 \mathrm{~mm}$ de base de medida e pacote de programas para aquisição e tratamento de dados (Blue Hill). Foram medidos o limite de escoamento (LE), limite de resistência $(L R)$, alongamento uniforme $(A u)$ e total $\left(A_{T}\right)$ e expoente de encruamento $(n)$.

\subsection{Determinação da Capacidade de Expansão de Furo}

Para execução do ensaio foi utilizada uma prensa universal Erichsen, modelo 145/60, com capacidade de força no punção e no prensa chapas de 60 tf. Os ensaios foram realizados segundo a norma ISO/TS 16630 [3], a partir de três corpos de prova para cada ciclo térmico na dimensão $140 \times 140 \mathrm{~mm}$ e furo puncionado de $10 \mathrm{~mm}$ de diâmetro, com folga de corte de aproximadamente $12 \%$. A força de prensa chapas utilizada foi de $50 \mathrm{tf}$ e a velocidade do punção foi de $30 \mathrm{~mm} /$ minuto.

\section{RESULTADOS E DISCUSSÃO}

\subsection{Caracterização Microestrutural}

A microestrutura do aço na condição de laminado a frio não recozido se apresentou deformada, formada basicamente de $80 \%$ de ferrita, sendo o restante composto de martensita (M), bainita (B) e perlita esboroada.

Em relação aos resultados dos ensaios dilatométricos, as temperaturas de início $\left(\mathrm{Ac}_{1}: 708^{\circ} \mathrm{C}\right)$ e final $\left(\mathrm{Ac}_{3}: 869^{\circ} \mathrm{C}\right)$ da transformação austenítica foram determinadas mediante a análise das curvas de variação dimensional do corpo de prova (dilatação) e suas derivadas em relação ao tempo e a temperatura, conforme mostrado na figura 2. Além disso, determinou-se a temperatura de fim da dissolução da cementita na perlita $\left(\mathrm{Ac}_{\theta}: 748^{\circ} \mathrm{C}\right)$ e a temperatura de máxima taxa de transformação $\alpha / \gamma\left(\mathrm{TMT}: 832^{\circ} \mathrm{C}\right)[4]$.

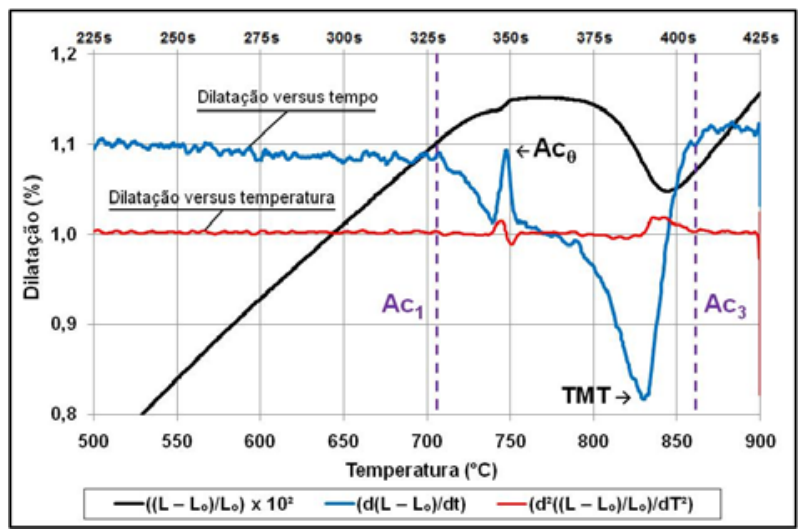

Figura 2. Curva de variação dimensional do corpo de prova e suas derivadas (dilatação versus tempo e dilatação versus temperatura) obtidas via dilatometria. 
Ainda de acordo com os resultados dos ensaios dilatométricos, as frações obtidas de segundo constituinte após têmpera ao final das isotérmicas de encharque a $740^{\circ} \mathrm{C}$ e $780^{\circ} \mathrm{C}$ foram em média $31,5 \%$ e $67.2 \%$, respectivamente. Na figura 3 são apresentadas as microestruturas obtidas. Considerando que a austenita formada ao final do encharque foi transformada em segundo constituinte durante a têmpera, pode-se afirmar que essas frações volumétricas correspondem às quantidades de austenita formadas no recozimento intercrítico [5].

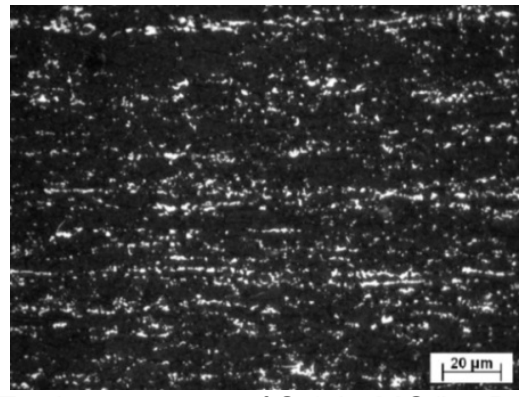

(a) Encharque a $740^{\circ} \mathrm{C}$ (via MO/Le Pera)

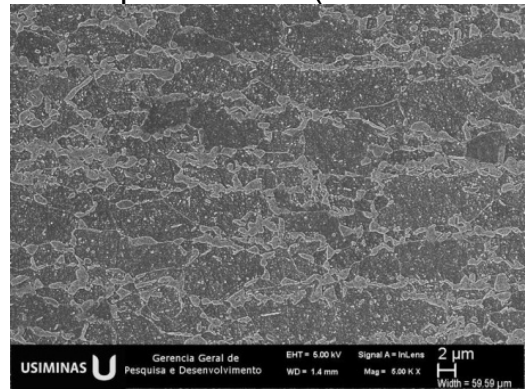

(c) Encharque a $740^{\circ} \mathrm{C}$ (via MEV/Nital).

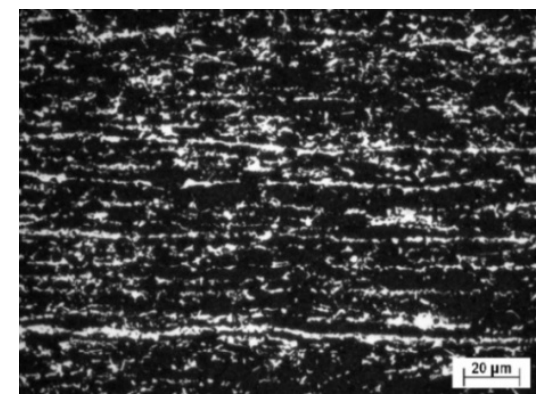

(b) Encharque a $780^{\circ} \mathrm{C}$ (via MO/Le Pera).

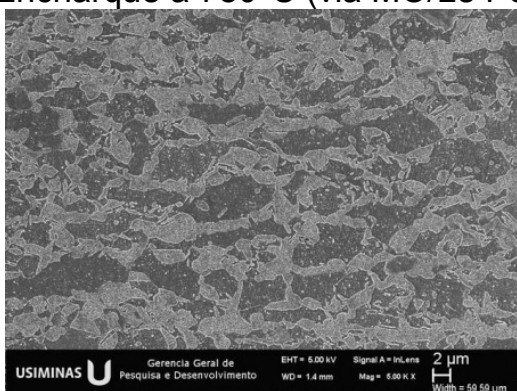

(d) Encharque a $780^{\circ} \mathrm{C}$ (via MEV/Nital).

Figura 3. Microestruturas obtidas após têmpera com gás hélio ao final dos encharques dos ciclos térmicos via ensaios dilatométricos.

Nesse estudo se constatou que até aproximadamente a temperatura de $748^{\circ} \mathrm{C}\left(\mathrm{Ac}_{\theta}\right)$ a austenita se desenvolveu dentro da própria perlita e/ou regiões ricas em carbono, sendo a cinética desse processo controlada pela difusividade do carbono. Acima desta temperatura, tendo-se dissolvidos todos os carbonetos, a nucleação da austenita se estendeu aos contornos de grãos da ferrita, o que pode ser comprovado pela quantidade de segundo constituinte disperso na matriz ferrítica $[6,7]$.

Outro fato que corrobora com essa hipótese é a presença do constituinte MA (martensita-austenita) nas microestruturas simuladas com encharque a $780^{\circ} \mathrm{C}$ através do HDPS, conforme mostrado na figura 4. Isso se deve potencialmente a dois fatores: (1) formação de austenita no interior dos grãos de ferrita diante da elevada temperatura de encharque e (2) o teor de manganês reduzindo a atividade do carbono no interior da austenita, retardando as transformações martensítica e bainítica e promovendo a formação do constituinte MA $[7,8]$.

As microestruturas obtidas a partir das simulações com encharque a $740^{\circ} \mathrm{C}$ via HDPS, possuem aspecto tipicamente bifásico, conforme a figura 4. Existe clara distinção entre os grãos ferríticos e as ilhas de martensita, embora não se tenha alcançado o pleno desenvolvimento microestrutural, reflexo da baixa temperatura de encharque no campo intercrítico, que resultou na incompleta dissolução dos carbonetos associada à baixa nucleação de austenita. Diferentemente do que foi observado nas amostras simuladas com encharque a $780^{\circ} \mathrm{C}$, as quais apresentaram microestruturas mais refinadas, com maiores frações de segundo constituinte 
dispersas na matriz ferrítica, e como já anteriormente mencionado, com a presença do constituinte MA.

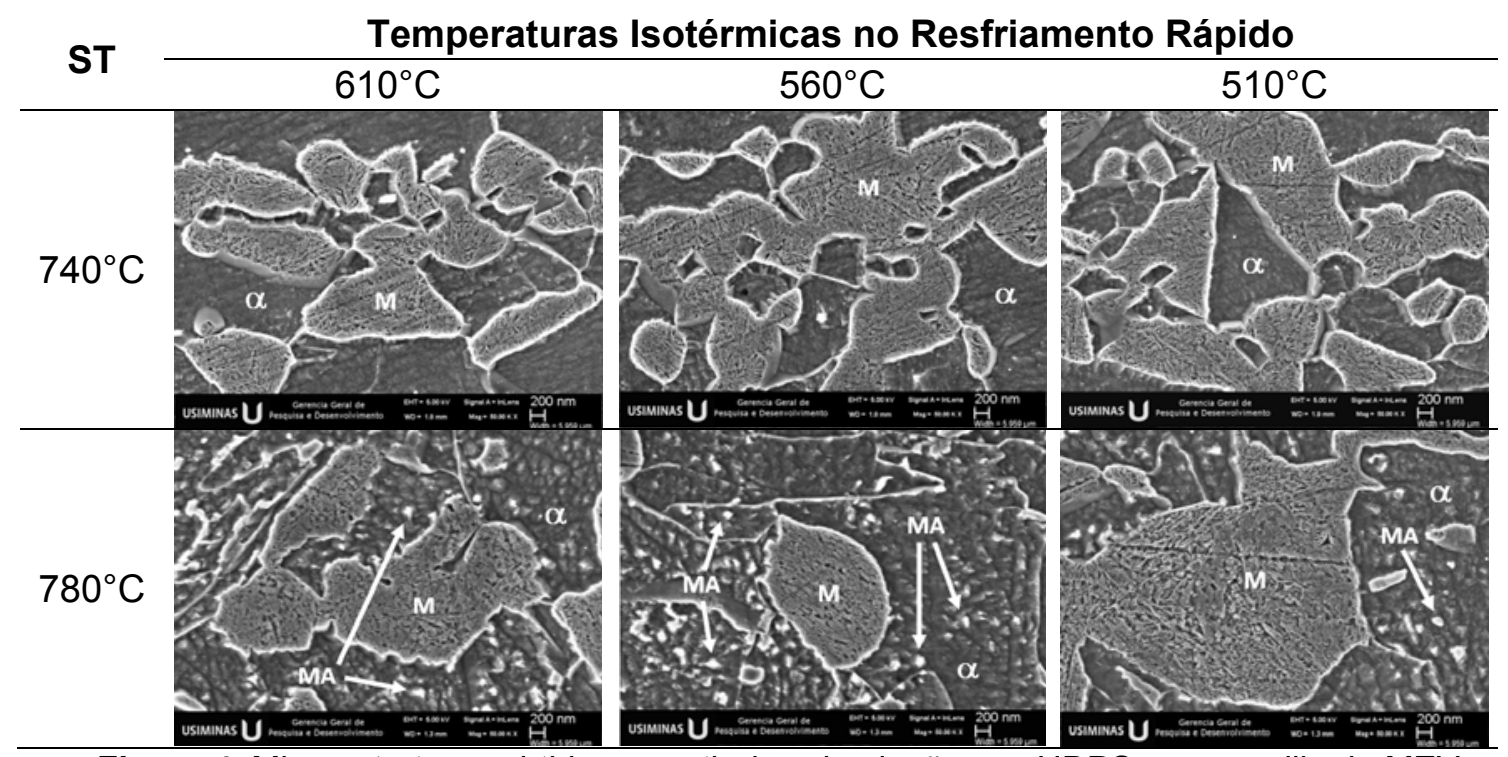

Figura 4. Microestruturas obtidas a partir das simulações no HDPS, com auxilio do MEV.

Em suma, as análises microestruturais de cada amostra simulada através do HDPS evidenciaram um aumento das frações de segundo constituinte diante do aumento da temperatura de encharque. Associado a este fato, também se verificou uma tendência de crescimento destas frações à medida que se diminuiu a temperatura isotérmica durante o resfriamento rápido após o encharque a $780^{\circ} \mathrm{C}$, conforme mostrado na figura 5 .



Figura 5. Representação gráfica das frações volumétricas dos constituintes microestruturais das amostras simuladas no HDPS.

\subsection{Resultados de Propriedades Mecânicas em Tração}

Como reflexo do desenvolvimento microestrutural aquém do necessário para formação de maiores quantidades de segundo constituinte, as simulações com encharque a $740^{\circ} \mathrm{C}$ apresentaram valores de LE, LR e ductilidade inferiores aos alcançados nas simulações com encharque a $780^{\circ} \mathrm{C}$, independente da temperatura isotérmica no resfriamento rápido. Nas simulações com encharque a $780^{\circ} \mathrm{C}$ se verificou uma clara tendência de elevação do LE e LR a medida que se diminuiu a temperatura isotérmica no resfriamento rápido, conforme a figura 6 , o que está relacionado às maiores frações de segundo constituinte, sobretudo, nas simulações com isotérmicas de $510^{\circ} \mathrm{C}$ e $560^{\circ} \mathrm{C}$ no resfriamento rápido, as quais atenderam 
satisfatoriamente o requisito mínimo de $800 \mathrm{MPa}$ de resistência mecânica. Em contrapartida, houve aumento da razão elástica (LE/LR), em função dos maiores valores de LE, conforme mostrado na figura 7.

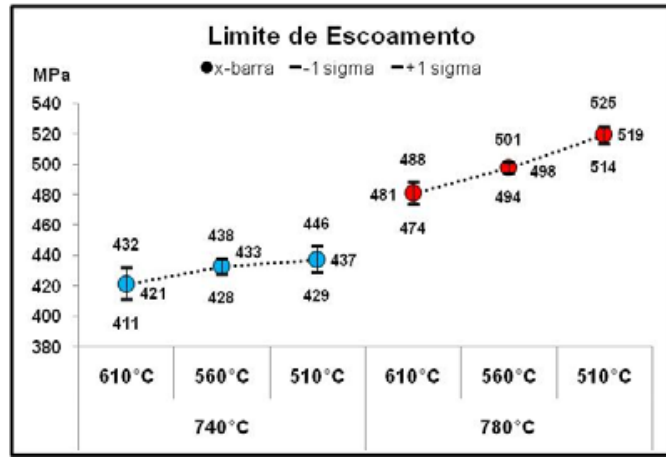

(a)

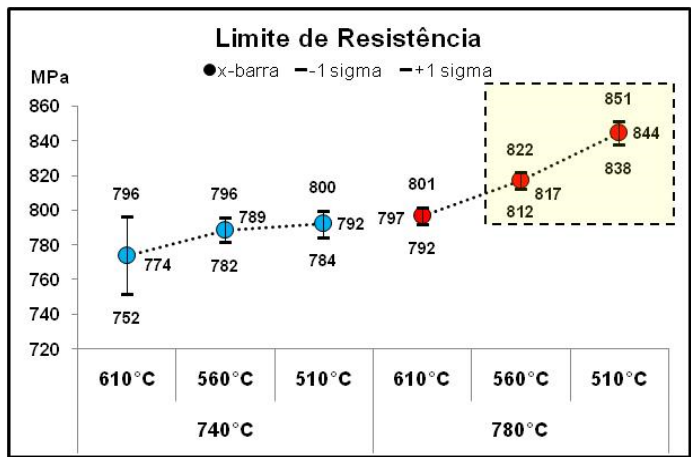

(b)

Figura 6. Resultados de limite de escoamento (a) e de resistência (b) em função dos ciclos térmicos simulados no HDPS.



Figura 7. Valores de razão elástica (LE/LR) em função dos ciclos térmicos simulados no HDPS.

De acordo com a literatura [5,9], as propriedades mecânicas dos aços bifásicos são ajustadas, principalmente, pela fração volumétrica do segundo constituinte e pela quantidade de carbono contido no mesmo. Conforme a figura 8 foi avaliada 0 relacionamento entre estas características e verificada boa correlação linear entre os valores de LE, LR e as frações de segundo constituinte presentes nas microestruturas obtidas nas simulações no HDPS.



(a)

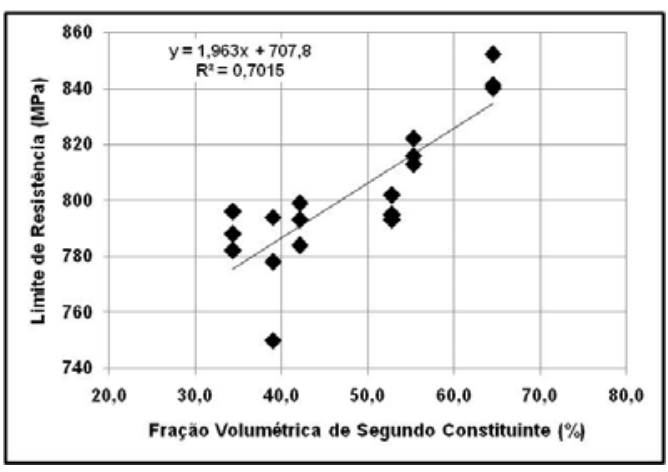

(b)

Figura 8. Influência do segundo constituinte nos valores de limite de escoamento (a) de resistência (b) obtidos a partir das simulações via HDPS.

A ductilidade (medida pelo alongamento) verificada nas simulações com temperatura de encharque a $740^{\circ} \mathrm{C}$ foi afetada pela presença de carbonetos não dissolvidos na 
ferrita, atuando como barreiras ao deslizamento de discordâncias, associada às pequenas frações de segundo constituinte com maiores teores de carbono e, por consequência, de maiores durezas, contribuindo para incompatibilidade plástica com a ferrita, em detrimento do alongamento uniforme e total [9].

Em relação à ductilidade obtida nas simulações com encharque a $780^{\circ} \mathrm{C}$, a austenita formada em elevadas temperaturas de encharque contém baixo teor de carbono, originando frações de segundo constituinte de menores durezas. De acordo com Llewellyn [5] e Yakubovsky [9], esse fenômeno combinado com a formação da ferrita epitaxial (novos grãos de ferrita isentos de precipitados com a mesma orientação cristalina da ferrita remanescente, sem contorno entre elas, nucleados durante a etapa de resfriamento lento) contribuem significativamente para o aumento da ductilidade, conforme verificado na figura 9.

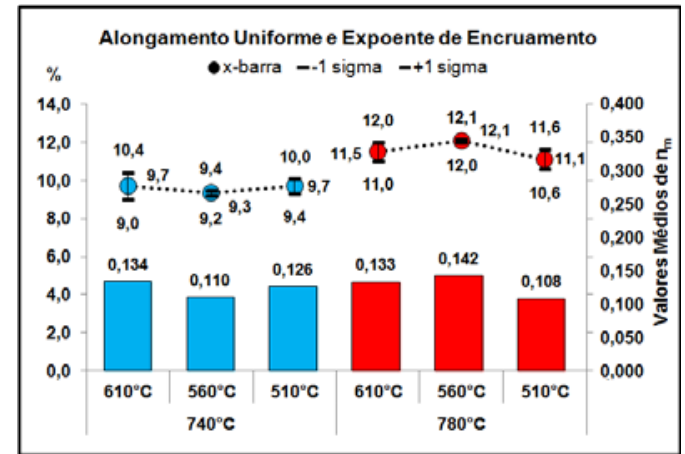

(a)

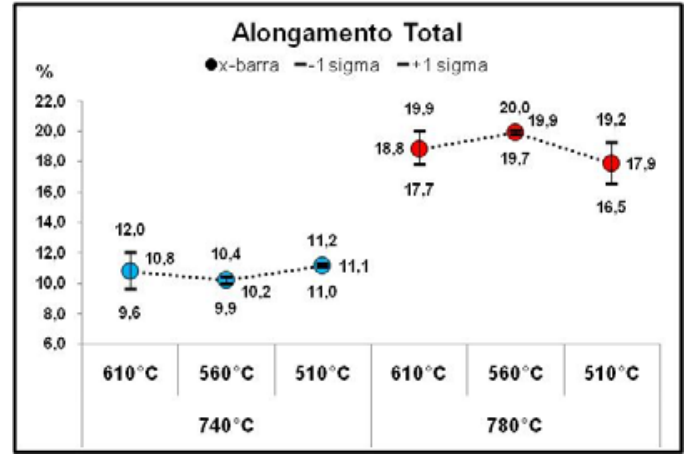

(b)

Figura 9. Resultados dos valores médios de alongamento uniforme e expoente de encruamento (a) e alongamento total (b) em função dos ciclos térmicos simulados no equipamento HDPS.

\subsection{Resultados de Expansão Cônica de Furo}

De acordo com a literatura, para o êxito nas operações de expansão de furo (flangeamento) em aços bifásicos alguns autores ressaltam o balanço da dureza entre os constituintes presentes no aço, como Fujita [10] e co-autores, que privilegiam uma microestrutura homogênea (bainítica); enquanto outros autores, como Lee [11] e co-autores, afirmam que uma maior ductilidade resultante de maiores frações de ferrita epitaxial, com a presença do segundo constituinte finamente disperso na matriz ferrítica, favorecem o flangeamento. Neste estudo não foram observadas diferenças significativas na capacidade de expansão de furo entre as simulações realizadas no HDPS, tendo as amostras simuladas com encharque a $780^{\circ} \mathrm{C}$ resultados ligeiramente superiores aos obtidos com encharque $740^{\circ} \mathrm{C}$, conforme a figura 10 .

Nas simulações com encharque a $740^{\circ} \mathrm{C}$ acredita-se que a maior dureza do segundo constituinte (formada a partir de austenita com elevado teor de carbono, reflexo da baixa temperatura de encharque no recozimento intercrítico) tenha promovido a nucleação de trincas nas bordas nos flanges, causada pela incompatibilidade plástica entre a ferrita e o segundo constituinte. Acredita-se também que os resultados não foram piores devido às elevadas frações de ferrita obtidas (em torno de $60 \%$ ). Neste caso em particular, possivelmente o encruamento da ferrita retardou a nucleação das trincas nas bordas dos flanges.

Com respeito às amostras com encharque a $780^{\circ} \mathrm{C}$, apesar das maiores frações de segundo constituinte, acredita-se que houve um melhor balanço entre as durezas dos mesmos e da ferrita, refletindo em um ligeiro aumento nos percentuais de 
expansão cônica de furo (ECF), o que estaria em consonância com o trabalho de Fujita [10].

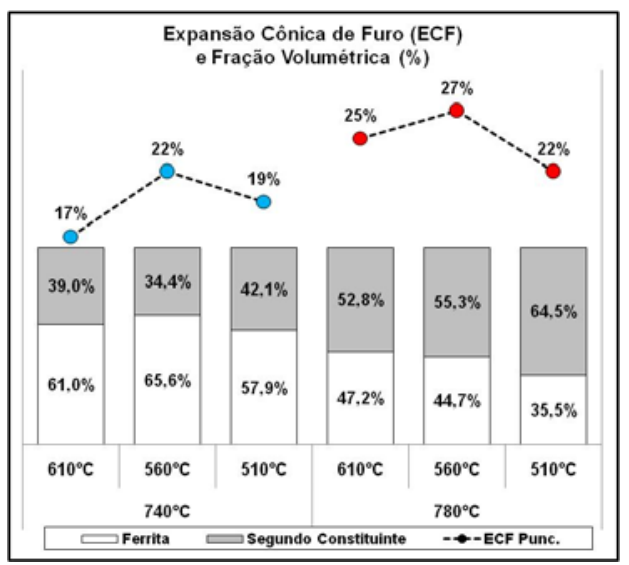

Figura 10. Resultados dos valores médios da expansão cônica de furo (ECF) dos corpos de prova puncionados versus as frações volumétricas de constituintes encontradas a partir de cada simulação no equipamento HDPS.

Todavia, um fato relevante foi o melhor desempenho nos ensaios de expansão cônica de furo das amostras simuladas com a temperatura isotérmica de $560^{\circ} \mathrm{C}$ no resfriamento rápido. De acordo com os ensaios dilatométricos, estas isotérmicas se situaram dentro do campo bainítico, o que provavelmente contribui para um melhor balanço de dureza entre os constituintes microestruturais, assim elevando a capacidade de expansão de furo [10].

Foi observada correlação positiva entre os resultados de expansão cônica de furo, alongamento uniforme e total. Este fato está diretamente relacionado com a maior ductilidade obtida nas amostras simuladas com encharque a $780^{\circ} \mathrm{C}$ (ver figura 11) e alinhado com as discussões do trabalho de Lee [11].



(a)

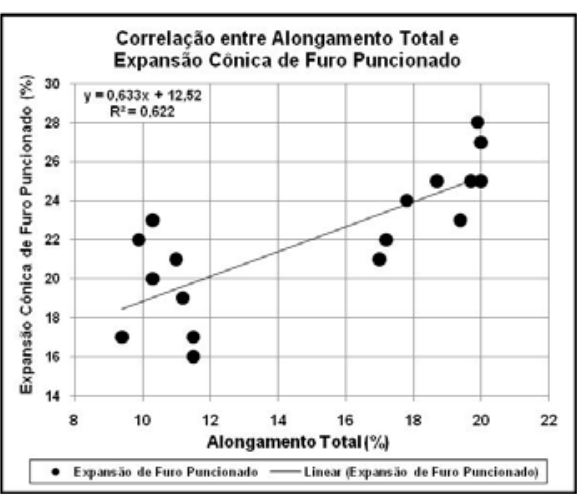

(b)

Figura 11. Correlação entre os resultados de expansão cônica de furo puncionado e de alongamento uniforme (a) e total (b).

\section{CONCLUSÃO}

A caracterização microestrutural evidenciou que a temperatura de encharque de $740^{\circ} \mathrm{C}$ não foi suficiente para dissolução completa dos carbonetos, limitando-se à recristalização total da ferrita e à nucleação de pequenas frações de austenita no recozimento intercrítico, o que resultou em baixas frações de segundo constituinte em todas as condições avaliadas. Com isso, o limite de resistência mínimo de $800 \mathrm{MPa}$ não foi alcançado. Além disso, os resultados de ductilidade e expansão de 
furo se mostraram aquém dos obtidos nas simulações com encharque a $780^{\circ} \mathrm{C}$. Por sua vez, as simulações com temperatura de encharque de $780^{\circ} \mathrm{C}$ e temperaturas isotérmicas de $510^{\circ} \mathrm{C}$ e $560^{\circ} \mathrm{C}$ no resfriamento rápido apresentaram resultados satisfatórios, atendendo o limite de resistência mínimo, com boa ductilidade e capacidade de expansão de furo ligeiramente superior à obtida nas simulações com encharque a $740^{\circ} \mathrm{C}$, características influenciadas pelas maiores frações de segundo constituinte, especialmente pela presença do constituinte MA (martensita-austenita).

\section{Agradecimentos}

A todos que contribuíram para execução deste trabalho, especialmente, a Universidade Federal de Minas Gerais - UFMG, CAPES-PROEX e USIMINAS.

\section{REFERÊNCIAS}

1. LIU, H., LI, F., SHI, W., SWAMINATHAN, S., HE, Y., ROHWERDER, M., LIN, L. Challenges in hot-dip galvanizing of high strength dual phase steel: Surface selective oxidation and mechanical property degradation. Surface \& Coatings Technology, 2012, p.3428-3436.

2. NORMA ASTM A 370: Test methods and definitions for mechanical testing of steel products - American Society for Testing and Materials, Edition: 2012.

3. TECHNICAL SPECIFICATION (ISO TS 16630): Metallic materials - Method of hole expanding test. Edition: 2003.

4. SAN MARTÍN, D., DE COCK, T., GARCÍA-JUNCEDA, A., CABALLERO, F. G., CAPDEVILA, C., GARCÍA de ANDRÉS, C. Effect of Heating Rate on Re-austenitisation of Low Carbon Niobium Microalloyed Steel. Materials Science and Technology, vol. 24, 2008, p. 266-272.

5. LLEWELLYN, D. T., HILLIS, D. J. Dual Phase Steels - Review. Ironmaking and Steelmaking, vol. 23, n. ${ }^{\circ} 6,1996$, p.471-478.

6. MOHANTY, R. R., GIRINA, O. A., FONSTEIN, N. M. Effect of Heating Rate on the Austenite Formation in Low-Carbon High-Strength Steels Annealed in the Intercritical Region. Metallurgical and Materials Transactions A, vol. 42A, 2011, p.3680-3690.

7. SPEICH, G. R., DEMAREST, V. A., MILLER, R. L. Formation of Austenite During Intercritical Annealing of Dual-Phase Steels. In: Metallurgical Transactions, vol. 12A, 1981. American Society for Metals and The Metallurgical Society of AIME, p.1419-1428.

8. WANG, S. C., YANG, J. R. Effects of Chemical Composition, Rolling and Cooling Conditions on the Amount of Martensite/Austenite (M/A) Constituent Formation in Low Carbon Bainitic Steels. Materials Science and Engineering A, vol. 154, 1992, p.43-49.

9. YAKUBOVSKY, O., KASPUTIN, M. Effect of New Ferrite on Strength-Ductility Balance of a High-Strength Water Quenched Dual Phase Sheet Steel, Materials Science and Technology Steel related Papers, 2006, p.267-275.

10. FUJITA, N., NONAKA, T., TOMOKIYO, T., TANIGUCHI, H. Development of Ultra-High Strength of $980 \mathrm{MPa}$, SAE International, 2007, p.51-55.

11. LEE, J., LEE, S. COOMAN, B. Effect of micro-alloying elements on the stretchflangeability of dual phase steel, Materials Science and Engineering A, vol. 536, 2012, p.231-238. 